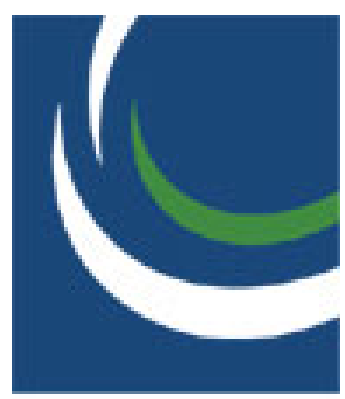

apsa

Committee Decisions under Majority Rule: An Experimental Study

Author(s): Morris P. Fiorina and Charles R. Plott

Source: The American Political Science Review, Vol. 72, No. 2 (Jun., 1978), pp. 575-598

Published by: American Political Science Association

Stable URL: http://www.jstor.org/stable/1954111

Accessed: 19/12/2013 14:41

Your use of the JSTOR archive indicates your acceptance of the Terms \& Conditions of Use, available at http://www.jstor.org/page/info/about/policies/terms.jsp

JSTOR is a not-for-profit service that helps scholars, researchers, and students discover, use, and build upon a wide range of content in a trusted digital archive. We use information technology and tools to increase productivity and facilitate new forms of scholarship. For more information about JSTOR, please contact support@ jstor.org.

American Political Science Association is collaborating with JSTOR to digitize, preserve and extend access to The American Political Science Review. 


\title{
Committee Decisions under Majority Rule: An Experimental Study *
}

\author{
Morris P. Fiorina And Charles R. Plott \\ California Institute of Technology
}

\begin{abstract}
This article reports the findings of a series of experiments on committee decision making under majority rule. The committee members had relatively fixed preferences, so that the process was one of making decisions rather than one of problem solving. The predictions of a variety of models drawn from Economics, Sociology, Political Science and Game Theory were compared to the experimental results. One predictive concept, the core of the noncooperative game without side payments (equivalent to the majority rule equilibrium) consistently performed best. Significantly, however, even when such an outcome did not exist, the experimental results did not display the degree of unpredictability that some theoretical work would suggest. An important subsidiary finding concerns the difference between experiments conducted under conditions of high stakes versus those conducted under conditions of much lower stakes. The findings in the two conditions differed considerably, thus calling into question the political applicability of numerous social psychological experiments in which subjects had little or no motivation.
\end{abstract}

\section{Introduction}

Committee decision making constitutes a long-standing concern of political scientists. ${ }^{1}$ Congressional committees have received a great deal of attention, ${ }^{2}$ but committees at other levels of government have not escaped notice. Generally, it is fair to say that committee research is stronger on the empirical side than on the theoretical. The primary emphasis lies on understanding a specific committee and perhaps the larger political system (e.g., Congress) within which the committee exists. Only a secondary emphasis lies on formulating generalizations which could be applied to committee situations removed from those studied. And seldom is a committee study regarded simply as a data source against which broad theoretical generalizations could be checked. ${ }^{3}$

*The financial support for this research was provided by the National Science Foundation, Economics and Political Science Programs. We gratefully acknowledge this support. For their invaluable research assistance and healthy skepticism we thank Randy Calvert, Linda Cohen, James Hong, and Darwin Niekirk. We also wish to thank John Jackson whose comments helped shape some aspects of this research.

${ }^{1}$ Woodrow Wilson, Congressional Government (New York: Meridian, 1956).

${ }^{2}$ Ralph K. Huitt, "The Congressional Committee: A Case Study," American Political Science Review, 48 (June 1954), 340-65; Richard E. Fenno, The Power of the Purse (Boston: Little, Brown, 1966).

${ }^{3}$ For example, in the introduction to The Power of the Purse, Fenno writes (p. xiii):
One finds quite a different emphasis in the mathematics, operations research, and economics literature. There one discovers numerous general models of committee decision processes, most of which build on gametheoretic and social choice-theoretic ideas. ${ }^{4}$ But why are the general principles found here so seldom applied by political scientists? It is true that the theoretical literature is quite technical, and most political scientists have little mathematical training. But we daresay that political scientists would be crowding into mathematics classes if they really believed that the technical literature had much to offer.

No doubt a more important reason for the

The aims of the book are threefold. In order of their likely relevance and persuasiveness for the reader they are: first, to provide an empirical description of the contemporary appropriations process in Congress; second, to demonstrate the importance of the committee-centered analysis for increasing an understanding of Congress; and third, to suggest the usefulness of certain bits of theory for students of Congress and its committees.

${ }^{4}$ Charles R. Plott, "Axiomatic Social Choice Theory: An Overview and Interpretation," American Journal of Political Science, 20 (August 1976), 511-96; William Riker and Peter Ordeshook, An Introduction to Positive Political Theory (Englewood Cliffs, N.J.: Prentice-Hall, 1973), passim; Peter Fishburn, The Theory of Social Choice (Princeton, N.J.: Princeton University Press, 1973); John Ferejohn and Morris Fiorina, "Purposive Models of Legislative Behavior,". American Economic Review Proceedings and Papers, 65 (May 1975), 407-14. 
lack of contact between mainstream political science and the technical literature is the difficulty in evaluating the latter. The models embody a curious mixture of positive and normative concerns. They are developed and advanced without a hint of possible operational definitions-one can find proof upon proof, but one searches in vain for a detailed discussion of exactly how and when a model should be applied. By relying. almost solely on logical validity, the technical literature has spawned many generalizations. But applied scientists simply cannot tell which of these might be usefully employed in field research. And they have neither the inclination nor the training to familiarize themselves with them all.

If theorists blithely continue to prove more theorems, and applied scientists doggedly continue to gather more data, at some point data and theory might miraculously conjoin. But we regard such a union as more likely to result from a determined effort than from a fortuitous accident. We have begun a program of research intended to bring together formal models and actual behavior. In this paper we report on the initial section of our work, a program of experimental research into the decision processes of small committees operating under majority rule.

We are quite aware of (and even share) the discipline's skepticism about the usefulness of experimental methods. What makes us believe, for example, that we can use college students to simulate the behavior of Congress members? Nothing. Our beliefs are much more modest. We intend to use the laboratory as a screen for basic ideas: if a given model does not predict well relative to others under a specified set of conditions in the controlled world of the laboratory, why should it receive preferential treatment as an explanation of non-laboratory behavior occurring under similar conditions? While laboratory success by no means implies field study success for a model, laboratory failure raises grave doubts about a model's applicability in field studies. Thus, while we reject the suggestion that the laboratory can replace creative field researchers, we do maintain that it can help them decide which ideas deserve further consideration.

There are a number of other problems which we do not wish to avoid. Rather than raise them in an introduction, however, we prefer to consider them in the light of what we have done. Thus, additional discussion of our particular brand of experimental methodology appears in the concluding section of this article.

\section{The Committee Process}

We constructed the experimental setting to be a simplified case of the general class of committees which we wish to understand. This class of committees is defined by four conditions:

a. Individual committee members are not uncertain about the consequences of any committee decision, i.e., they fully understand the effect which alternative committee decisions will have on them.

b. Committee members have clear, constant preferences over the objects of the committee decision. The committees are making decisions about things that matter to them. They are not solving problems or making judgments about things for which they have no personal preference.

c. There is no previously fixed parliamentary procedure other than minimal rules of order and majority rule.

d. There are no extra-committee agreements or private deliberations among subsets of committee members.

Basically, we wish to explain what goes on within the "black box" of committee decision making. We focus on the period after biological, sociological and psychological processes have operated to instill clear preferences in committee members. The question then is simply how a committee whose members have clear, conflicting preferences arrive at a decision in the simple institutional setting we create. Clearly, the political world we have designed lacks the institutional complexity of more naturally occurring political committees, and it is possible that the existence of alternative conditions might induce behavior different from that which occurs in our simple situations. But we believe that our experimental design captures the essence of the basic majority rule committee process. And, as it turns out, for this most basic committee process several models work quite well indeed, while many other proposed models do not work at all.

\section{Experimental Procedures, Setting and Design}

Procedures and Subjects. The research consists of 65 committee decision-making sessions. All the committees were five-person and all made decisions by majority rule. Subjects in the experiments were typically students from the University of Southern California, Pasadena 
City College, California State University at Los Angeles, and Los Angeles City College. 5 They were recruited from the classes of cooperating instructors and in cafeterias and other areas where students congregate. Each subject was permitted to participate in only one experimental session. Post-experiment conversations with instructors and subjects indicated that the subjects were cooperative in declining to discuss the experiment with outsiders after participating. Thus, subjects generally knew little or nothing about the experiment before reading the instructions.

Recruits were asked to appear at a designated time and place. At the maximum, four experiments were conducted simultaneously (20 subjects) but a few extra subjects always were recruited in order to assure the necessary number. Extras were paid $\$ 2.00$ for time and trouble and dismissed (none was permitted to observe). Once the recruits were assembled, assignments to committees and assignments to positions within committees were determined randomly. After reading the instructions (Appendix A) each committee went to a separate meeting room where deliberations immediately began.

Experimental Setting. The substance of the decision was simple. Each committee was asked to select a single point on the blackboard by majority rule. A coordinate system was drawn on the blackboard and each subject was assigned a payoff function defined over ordered pairs of the coordinate system. That is, subject $i$ was assigned a payoff function $U^{i}\left(x_{1}, x_{2}\right), i=1$, $2,3,4,5$, which indicated the amount of money he or she would receive from the experimenter expressed as a function of the point, $\left(x_{1}, x_{2}\right)$ chosen by the committee. (See Appendix B for an example, and Appendix C for all functions.) The instructions clearly stated that no threats, side-payments or postexperiment deals were permissible. In fact, our instructions prohibited any discussion of monetary amounts. ${ }^{6}$ So as long as individuals prefer

${ }^{5}$ An occasional working adult (e.g., gardener, secretary) appeared among our subjects. Our subjects included members of racial minorities and women. We are aware that some social psychologists prefer subject populations to be racially or sexually homogeneous. But the class of models in which we are interested gives us no reason to differentiate among blacks, whites, chicanos, men and women.

${ }^{6}$ This restriction serves two functions. First, it enhances control over the experiment. Outside deals which induce preference changes in subjects but not in more money to less, their preferences for points on the blackboard are represented ${ }^{7}$ by the functions $U^{i}\left(x_{1}, x_{2}\right)$.

This setting seems to assure that our committees were of the type designated by conditions (a) and (b) in section 2. There appears to be little uncertainty and, as long as the functions $U^{i}\left(x_{1}, x_{2}\right)$ have adequate slope, there is no general indifference. The method of recruitment assured that condition (d) was satisfied. This leaves only (c) open to operational question.

The committees made their decisions under a simple set of parliamentary procedures. Each committee began at the point $(200,150)$. That is, the status quo in each experiment was the extreme northeast point in the issue space. Upon recognition by the chair (experimenter), any subject could propose an amendment (no second required) to the motion on the floor. If it passed (possibly following discussion in sessions where discussion was allowed), the amendment became the new motion on the floor and the process continued. At any point during the experiment a motion to end debate was in order. If a majority consented, the motion on the floor was then voted up or down. If the motion passed, the experiment ended, and if it failed, the floor was again thrown open for amendments. Thus, each of our committees pushed a point around the blackboard until a majority voted to quit and go home. ${ }^{8}$ Subjects were paid in cash at the

the models are made difficult to negotiate. Furthermore, social stigmas regarding monetary endowments which also can induce uncontrolled preferences are minimized when monetary amounts are not public. Secondly, and perhaps more importantly, a cardinal measure of returns is not a general property of a broad range of committee processes. As in our experiments political decision makers can learn the order in which their fellow decision makers regard alternative proposals. They can attempt to communicate intensity through anger, other displays of emotion, and effort. But objectively given cardinal measures of returns are generally absent.

${ }^{7}$ For all $\left(x_{1}, x_{2}\right)$ and $\left(x_{1}^{\prime}, x_{2}^{\prime}\right)$ we know that $\left(x_{1}\right.$, $\left.x_{2}\right) R_{i}\left(x_{1}^{\prime}, x^{\prime}\right)$ if and only if $U^{i}\left(x_{1}, x_{2}\right) \geqslant U^{i}\left(x^{\prime} 1^{\prime}\right.$ $x_{2}^{\prime}$ ). So the binary relation $R_{i}$ is the preference relation.

${ }^{8}$ It is interesting to compare this stopping rule with that used $\rightarrow$ Peter Halfpenny and Michael Taylor, "An Experimental Study of Individual and Collective Decision Making," British Journal of Political Science, 3 (1973), 425-44. In their experiments Halfpenny and Taylor operationally defined an equilibrium as a 5-time winner, i.e., the experiment ended when a motion on the floor had defeated five alternative 
conclusion of the experiment.

The above-described process allows the parliamentary procedures to be essentially endogenous and as "natural" as possible, consistent with order. The recognition feature was followed only loosely, with many informal proposals made and rejected during discussions in those experiments without communication restrictions. A variety of more complex procedures can be found in use, and the behavior of committees under each must ultimately be examined. But we take our procedures to be an operational interpretation of condition (c).

Thus, we created five-person committees, induced preferences for outcomes among the committee members, and gave them a decision

motions. In our Series 1 experiments 24 proposals in 17 experiments defeated 5 or more alternatives but did not go on to become the group decision. Thus, 17 of 40 experimental outcomes would have been different had we taken action to stop the experiments rather than allowing them to take their course (and assuming such a rule left individual behavior unchanged). This example graphically illustrates the potential impact of procedural variations on experimental outcomes. rule (absolute majority rule). Beyond this they were free to do what they wanted. They sat together and communicated openly. If they wished to form coalitions, fine. If they wished to be "fair," fine. If they wished to attempt to maximize group gain, fine. If they wished to do nothing, fine. The lack of structure imposed by our instructions was demonstrated by the fact that subjects regularly asked "What are we supposed to do?" ("Get what's best for ourselves?" "Do what's fair?" etc.) We shrugged off such questions with a poker-faced, "Whatever you want," and read again the relevant sections of our instructions.

\section{Experimental Series and Competing Models}

Experimental Series. The three separate series reported here differ according to the induced preference configuration. These differences are reflected in Figure 1 for Series 1, Figure 2 for Series 2, and Figure 3 for Series 3, where the five points are the points of maximum payoff for subjects $1,2,3,4$ and 5 , respectively. The circles on Figures 1 and 3 and the ellipses on Figure 2 indicate the shape of the indifference

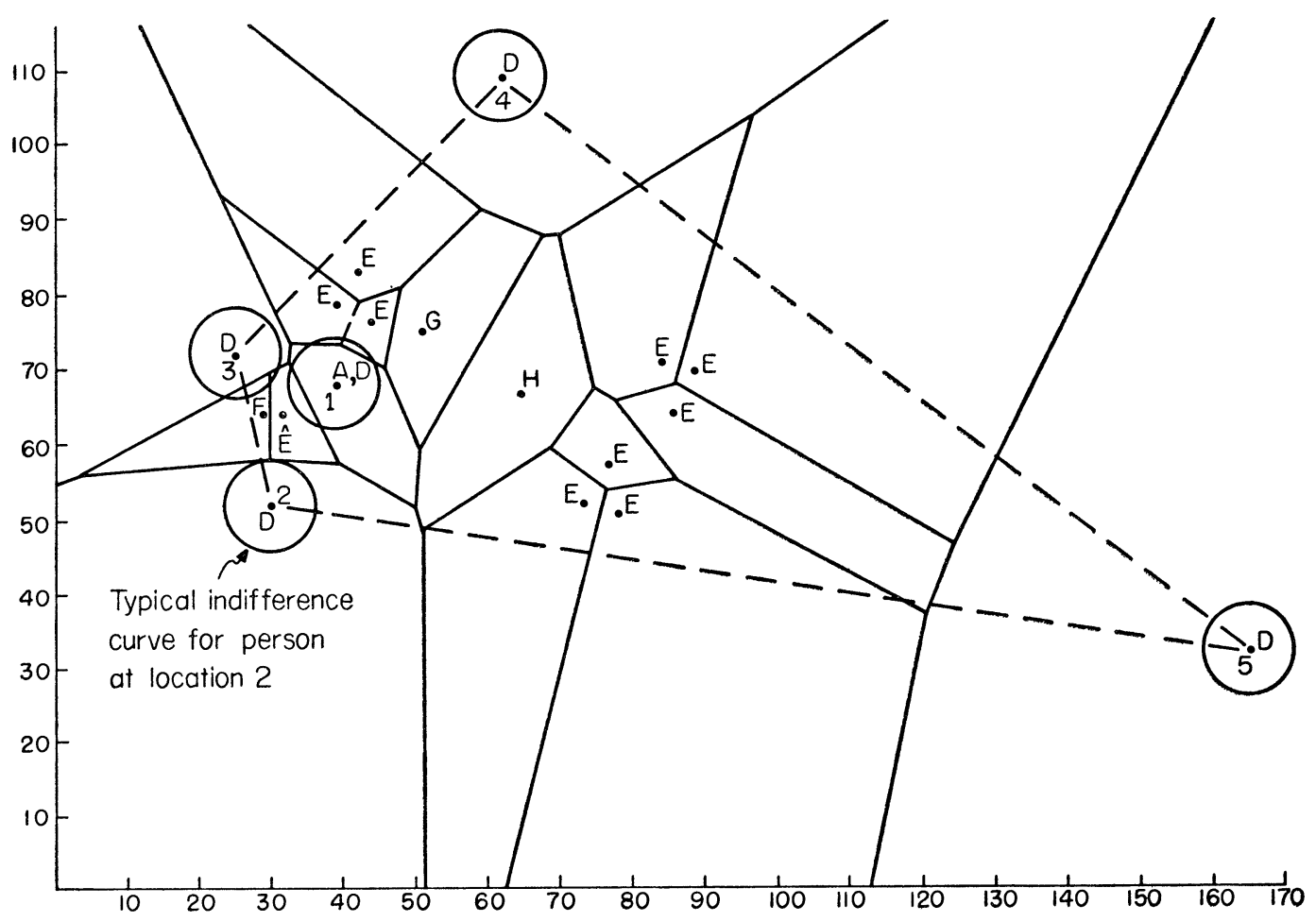

Figure 1. Series 1. Preference Configuration, Predicted Points and Partition of Space into Areas Closest to Predicted Points 


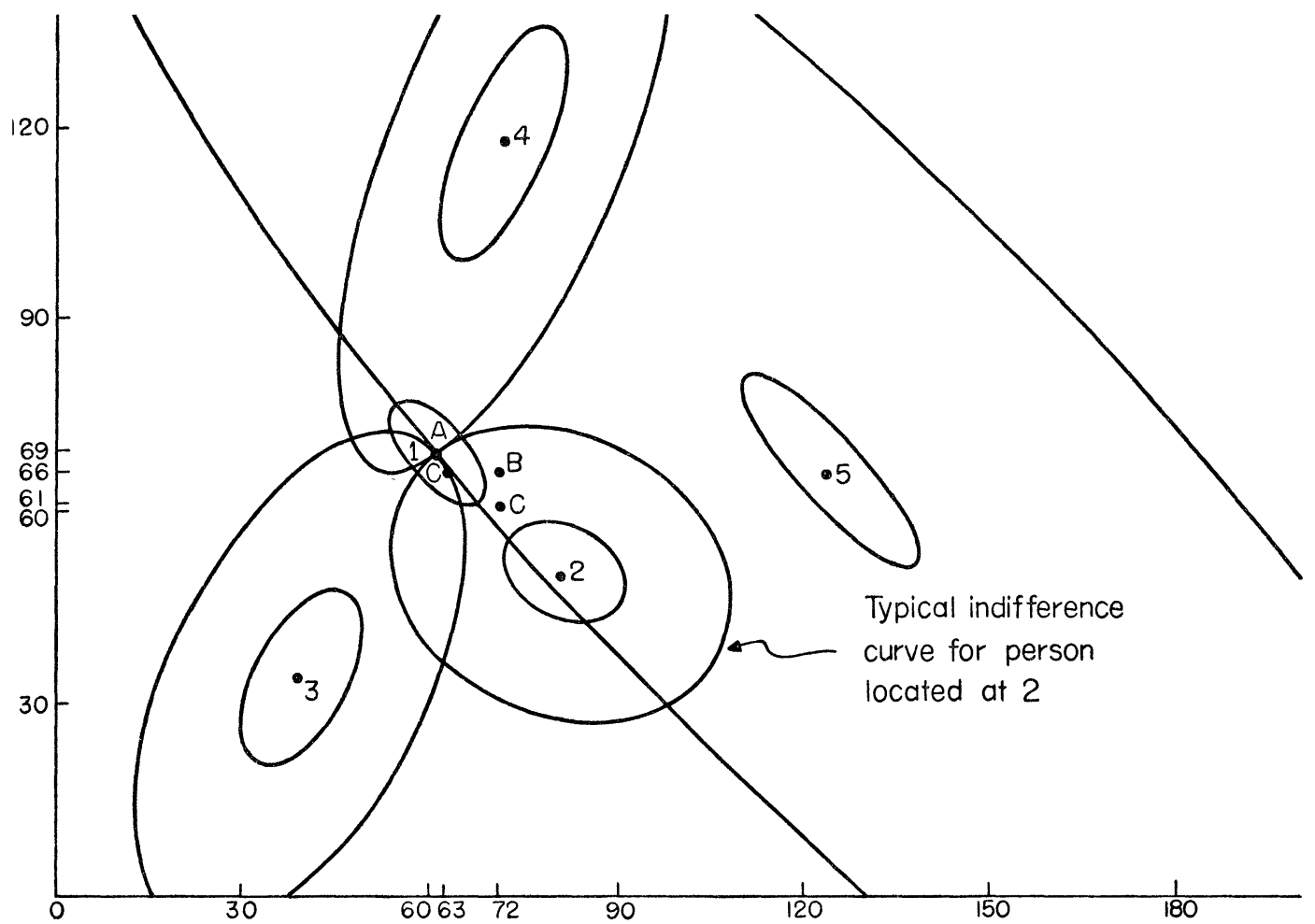

Figure 2. Series 2. Preference Configuration

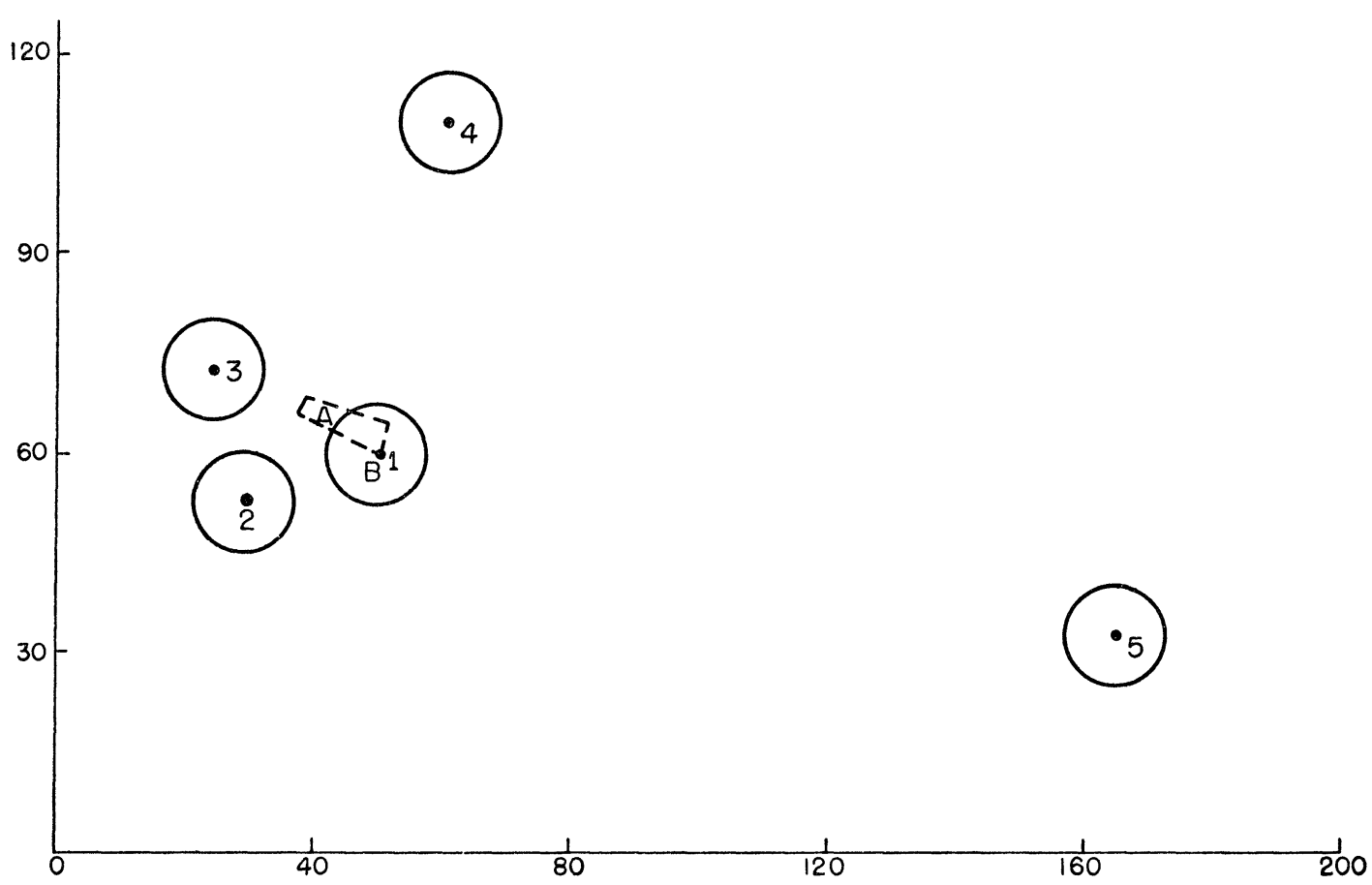

Figure 3. Series 3. Preference Configuration 
curves. The particular shapes and configurations were chosen strategically, as will be explained below.

Pilot experiments as well as some theoretical concerns suggested that in certain respects committees with small incentives behaved differently from committees with large incentives. In addition, pilot experiments suggested that the amount and type of communication made a systematic difference. This led to the examination of two different payoff magnitudes and two different communications conditions.

The 40 experimental sessions of Series 1 were divided into 4 subseries of 10 experiments each. The high-payoff condition employed payoffs similar to the example contained in Appendix B. The low-payoff condition specified much lower maximum payoffs and a smaller rate of loss as the outcome departed from the maximum. Appendix $\mathrm{C}$ gives full details. The communication condition varied from full communication-in which subjects could talk about anything they wished, other than the monetary aspects of their preferences-to no communication. In the latter condition subjects could do nothing except make proposals and vote.

As discussed below, Series 1 confirmed the initial hypothesis that low-incentive committees and high-incentive committees behave substantially differently. Because the models with which we are most familiar were most applicable to the high-payoff case, and because the communication condition seemed to make little difference in this case, we chose to follow the high-payoff, full-communication path in the remainder of our experiments.

Series 2 and 3 were both constructed to discriminate among models which gave identical, accurate predictions in the high-payoff case in Series 1. The logic behind these particular designs is explained in the following section.

Competing Models. Given our simple setting, there are a remarkable number of potentially applicable models which differ from one another in their assumptions about the behavior patterns of committee members. Although these models are motivated by reasonably well-articulated theories, it is often unclear how these theories apply to our situation, if at all. Thus, of necessity, we have taken the liberty of identifying predictions which incorporate the spirit of the respective theories. Possibly we have erred. If so, we invite aggrieved parties to correct us.

We have divided the available models into two broad classes according to the nature of the motivating theory. The theories which lie behind the first class, called egoistic, have the common view of decision makers as selfinterested maximizers, while the second class, non-egoistic, presupposes that committee members look beyond their individual interest to some type of collectively optimal, or consensus outcome. Egoistic theories can be subdivided further into four classes: game-theoretic, coalition-theoretic, voting-theoretic, and finally, agenda-based voting-theoretic.

Egoistic: Game-Theoretic. The theory of games without side payments and without transferable utility induces a natural way of modeling our committees. One may take the majority rule preference relation as the dominance relation. (There are other ways to form a dominance relation in our setting if patterns of communication, etc., are considered, but we propose this one as most natural.) From this base there are several alternative models, two of which are listed here.

1. Core. The core is the set of all undominated points. ${ }^{9}$ In our experiments the core is point $A$ in Series 1 and 2, and does not exist in Series 3.

2. Van Neumann-Morgenstern Solution. This set of points possesses internal and external stability properties. ${ }^{10}$ If a core exists, it will be included in all N-M solutions. In Series 1 and 2 there is a unique N-M solution, point A. In Series 3 we have not as yet succeeded in computing the main simple solution.

Egoistic: Voting-Theoretic. These models purport to specify which outcome will be adopted by a group of individuals each of whom votes sincerely, i.e., in accord with his or her personal preferences.

3. Voting Equilibrium. Introduced by Black and formally developed by Plott and Sloss, a voting equilibrium is a point which can be beaten by no other point in a binary contest characterized by sincere voting. ${ }^{11}$ Such a point is A on Figures 1

${ }^{9}$ R. J. Aumann, "A Survey of Cooperative Games Without Side Payments," in Essays in Mathematical Economics in Honor of Oskar Morgenstern, ed. M. Shubik (Princeton, N.J.: Princeton University Press, 1967).

${ }^{10}$ Aumann.

${ }^{11}$ Duncan Black, The Theory of Committee and Elections (Cambridge: Cambridge University Press, 
and 2. No such point exists on Figure 3. From a mathematical point of view the equilibrium is equivalent to the core of the appropriate cooperative game. But the core develops from concepts of coalition and joint strategy, whereas these concepts play no conceptual role in the theory of voting equilibrium. ${ }^{12}$

4. Min-Max Set. Developed by Simpson, this model predicts that the committee will gravitate to a set of points which have the property that the maximum number of individuals who would benefit from a move to some other point is minimized. ${ }^{13}$ The theory predicts point $\mathrm{A}$ for all except Series 3, where it predicts the set of points in the quadrilateral at the center of Figure 3.

5. Equilibrium under a City Block Metric. There are suggestions that the city block metric is in some sense more natural than the usual Euclidean metric, and that decision makers might impose such a metric even if there are indications that other metrics are more appropriate. ${ }^{14}$ If committee members' indifference curves are given by the city block metric, then

1958); Duncan Black and R. A. Newing, Committee Decisions with Complementary Valuations (London: William Hodge, 1951); Charles R. Plott, "A Notion of Equilibrium and Its Possibility under Majority Rule," American Economic Review, 57 (September 1967), $797-8 \rightarrow$ Judith Sloss, "Stable Outcomes in Majority Rule Voting Games," Public Choice, 15 (Summer 1973), 19-48.

${ }^{12}$ To draw a theoretical distinction between the formally equivalent concepts of core and voting equilibrium might strike some of our colleagues as unnecessary hair-splitting. To these skeptics we address one further point. In the typical case in which no core/equilibrium exists, where does one turn? If one has arrived at the core through the game-theoretic literature, one naturally turns to some other gametheoretic concept such as the N-M solution. But if one has arrived at the equilibrium through the votingtheoretic literature, one turns to some other votingtheoretic model such as the min-max set or an agenda theory. When it exists, the core/equilibrium is the intersection of several branches of theory. But that is not to deny that these branches are distinct.

${ }^{13}$ Paul B. Simpson, "On Defining Areas of Voter Choice," The Quarterly Journal of Economics, 83 (August 1969), 478-90.

$\stackrel{-}{\rightarrow}$ Douglas Rae and Michael Taylor, "Decision Rules and Policy Outcomes," British Journal of Political Science, 1 (1971), 71-90; also, Halfpenny and Taylor, "An Experimental Study." the equilibrium under majority rule with an odd number of voters is the unique intersection of the perpendicular hyperplanes through the median voter along each dimension. This point is $\mathbf{A}$ in Series 1 and $B$ in Series 2 and 3.

Egoistic: Agenda-Based Voting-Theoretic. The agenda procedures used by a committee can influence if not completely dictate the decision. ${ }^{15}$ This fact raises the possibility that there is some "natural" agenda which committees tend to use even if it is not formally specified. A general model of committee decisions would be interpreted as having two steps. First, there would be a prediction about which agenda the committee would adopt, and then, secondly, a prediction about how the committee will behave once an agenda has been adopted.

6. Obvious Agenda. Each individual will propose his or her best point at some time during the meeting. In particular, individual 1 will propose his or her best point: A. Notice that point A is preferred by a majority when put against any other point. Thus, if individuals vote sincerely, which tends to be the case with a fixed agenda, ${ }^{16} \mathrm{~A}$ will win whenever it is proposed. Although this reasoning suggests point $\mathrm{A}$ as a prediction for Series 1 and 2 , it makes no prediction for Series 3.

7. Dimension by Dimension Median. A "natural" procedure might be to choose a point along one dimension by majority rule, then, holding that point fixed, choose a point along a second dimension, hold it fixed, and continue in similar fashion until a choice has been made along each dimension. If committee members vote sincerely, the chosen point would be A in Series 1, B in Series 3, and points $\mathrm{C}$ in Series 2. (This model can make as many as $\mathrm{n}$ ! predictions, where $n$ is the dimensionality of the alternative space, depending upon the order in which the dimensions are considered.)

8. Sincere Binary Voting and Arbitrary Proposals. Suppose all motions involve a comparison of two outcomes-a motion

${ }^{15}$ Charles R. Plott and Michael E. Levine, "On Using the Agenda to Influence Group Decision: Theory, Experiments and Application," American Economic Review, forthcoming.

16Plott and Levine, "On Using the Agenda." 
on the floor and an amendment as outlined above. Amended motions are the new motion on the floor and are subject to amendment. Suppose further that individuals always vote sincerely and that amendments arise in some type of "hill climbing" fashion. The idea behind the model is, then, that the majoritydominance relation in some sense "drives" or "forces" the motion on the floor. For Series 1 the model predicts A. Because there is a transitive majority winner, with a "majority best" alternative, every chain of proposals leads there. For Series 2 the prediction is not clear because in this design cycles exist. Not every sequence in Series 2 will necessarily lead to the core or equilibrium. In Series 3 there is no core or equilibrium. McKelvey's theorem tells us that any two points in Series 3 can be connected via some majority-rule sequence. ${ }^{17}$ Thus, we interpret the model as saying that "anything can happen" in Series 3.

9. Agenda Manipulation. Plott and Levine hypothesize that some individuals have good intuition about the influence of the agenda. ${ }^{18}$ When no formally imposed agenda exists, the agenda becomes part of each individual's strategy set, and because it is known to greatly influence the outcome, the individual with the best intuition can use it to personal advantage. From this line of reasoning we predict the set of points $D$ of individual maximums.

Egoistic: Coalition Theories. Coalition theories agree that the decision will be made as if it results from a two-step process-although they might differ as to which step comes first. One step is the formation of a coalition with the power to institute decisions. The other step is the choice of decisions for the coalition to implement.

10. Minimum Winning Coalitions. The idea developed by Riker is that only coalitions of minimal winning size will form. ${ }^{19} \mathrm{We}$

${ }^{17}$ Richard McKelvey, "Intransitivities in Multidimensional Voting Models and Implications for Agenda Control," Journal of Economic Theory, 12 (1976), 472-82.

${ }^{18}$ C. R. Plott and Michael E. Levine, "On Using the Agenda."

${ }^{19}$ William Riker, $A$ Theory of Political Coalitions (New Haven: Yale University Press, 1962). take it that the implemented decision will be the "center" of the formed minimal winning coalition. There are ten such coalitions, so the model predicts that the outcome will be one of the ten points labeled E on Figure 1. This model was rejected in favor of other models in Series 1. Thus, its predictions were not carried forward to Series 2 and 3. (Any model rejected in one series was eliminated from further consideration.)

11. Resource Coalition Theories. Sociologists such as Gamson, and Komorita and Chertkoff hypothesize that once a coalition forms, the payoff to coalition members will follow an equity norm or parity norm based on the resources supplied by each coalition member. ${ }^{20}$ In our experiments the only "resource" a committee member possesses is a vote, and the situation is clearly one person-one vote. Thus, we interpret these models as identifying the point equidistant from the best point of each person in a coalition. Given these points, each person can rank each coalition according to his or her expected payoff in it. If some coalition is ranked best by all of its members, there is a presumption that it will form and behave according to expectations. In our experiment players $1,2,3$ should join and choose $\overline{\mathrm{E}}$.

12. Minimal Winning Coalition of Maximum Value. The coalition which could achieve the largest total payoff is $\{1,2,3\}$. The point $\mathbf{F}$ achieves this coalitional maximum. 21

$\rightarrow$ William Gamson, "A Theory of Coalition Formation," American Sociological Review, 26 (1961), 373-82; S. S. Komorita and Jerome M. Chertkoff, "A Bargaining Theory of Coalition Formation," Psychological Review, 80 (May 1973), 149-62.

${ }^{21}$ Obviously, our procedures (no communication of monetary amounts) work against any theory which specifies that the committee or a subgroup of it tries to achieve a group maximum (models 12 and 13). Of course, the political world also works against any such theory in that cardinal measures of preferences which group maximization theories presuppose are typically not available (footnote 3 ). And even if objectively known monetary payoffs are available, there still is no theoretical justification for asserting the equivalence of a maximum of group monetary payoff and group utility payoff. But for reasons discussed under model 13 we can not dismiss out-of-hand models which contain group or subgroup maximization processes. 
Non-Egoistic. These theories have in common the premise that principles more general than individual selfishness explain group decision making. We content ourselves with four possibilities.

13. Maximum Group Return. Even though individuals cannot express monetary amounts, they can and do express the intensity of their feelings by shows of emotion, willingness, or unwillingness to cooperate, etc. In such ways the group interaction could carry the process to a point which maximizes group return. ${ }^{22}$ If such behavior is observed, a deeper explanation could proceed in terms of some concept of group welfare. This is point $\mathrm{G}$ in Series 1 .

14. Fair Point. Pilot experiments suggested that a likely candidate for a "fair" outcome was the average of the points of individual maximum. This point also happens to be the centroid, the point which minimizes the sum of Euclidean distance from the points of individual maximum. ${ }^{23}$ In each series this point is designated $\mathrm{H}$.

15. Dominant Personality. Perhaps some individuals have such strong personalities that deference overrides any other incentives experimentally induced in the other individuals. The idea, as presented here, is in part a "straw man" since we have found no clear reference from which to draw it. Nevertheless, a feeling that variables like this are important seems pervasive. If it is true that individual preferences are substantially influenced in group interactions, then we would be prepared to look in this direction for an explanatory model. We take the prediction here to be neighborhoods around the individual maxima, points $\mathrm{D}$.

16. Obvious Point. Schelling's idea can be adapted to our scenario. ${ }^{24}$ Is there a

${ }^{22}$ Bernhardt Lieberman, "Combining Individual Preferences into a Social Choice," in Social Choice, ed. Bernhardt Lieberman (New York: Gordon and Breach, 1971), pp. 5-25.

${ }^{23}$ R. A. Hanson and P. M. Rice, "Policy Outcomes in Decision Making Groups," paper delivered at the annual meeting of the American Political Science Association, 1972.

${ }^{24}$ Thomas Schelling, The Strategy of Conflict (Oxford: Oxford University Press, 1960). "prominent" or "obvious" place to goperhaps other than one of the points outlined above? In each series there is one individual maximum in the interior of the convex hull of the individual maxima. We take the point $A$ in Series 1 and Series 2 and point $B$ in Series 3 as the obvious point predictions.

\section{Experimental Results}

Series 1. The Series 1 design affords an opportunity to make a first broad cut among the numerous models discussed in the preceding section. The design is such that the egoistic voting-theoretic, agenda-based voting-theoretic and game-theoretic models conflict with the egoistic coalition-theoretic and non-egoistic models. As mentioned above, pilot experiments suggested that both payoff size and amount of communication affected experimental outcomes. Thus, although most of the candidate models say nothing terribly precise about these variables, a class of models might possibly work well under one set off payoff/communication conditions, but not others. For example, we anticipated that the entire class of non-egoistic theories would perform better with communication and with low payoffs. Conversely, restricted communication and high payoffs would appear to maximize the chances of a good performance by certain of the egoistic theories. Thus, we conducted 40 experiments, 10 each in the 4 combinations of low/high payoffs, no/free communication described in section 4.

Table 1 contains the outcomes for the 40 experiments of Series 1 . The findings for the low and high payoff conditions differ, so we will discuss them separately.

The mean outcome in the high-payoff condition is almost exactly the point, A, of Figure 1. No other model of those under consideration predicts the experimental outcomes nearly so well. The apparently complex but conceptually simple Figure 4 graphically illustrates the comparative performance of the three classes of models. In Figure 4 each point identified in Figure 1 is enclosed by a shape which separates all points closer (in Euclidean distance) to it than to any other predicted point. For purposes of display we have pooled the observations from the two communications conditions. Clearly, the point A wins hands down. Fourteen of 20 outcomes are closer to it than to any other predicted point. One outcome is closer to the committee maximum than to any other point. Of the remainder, two are closest to the 
Table 1. Experimental Outcomes: Series 1

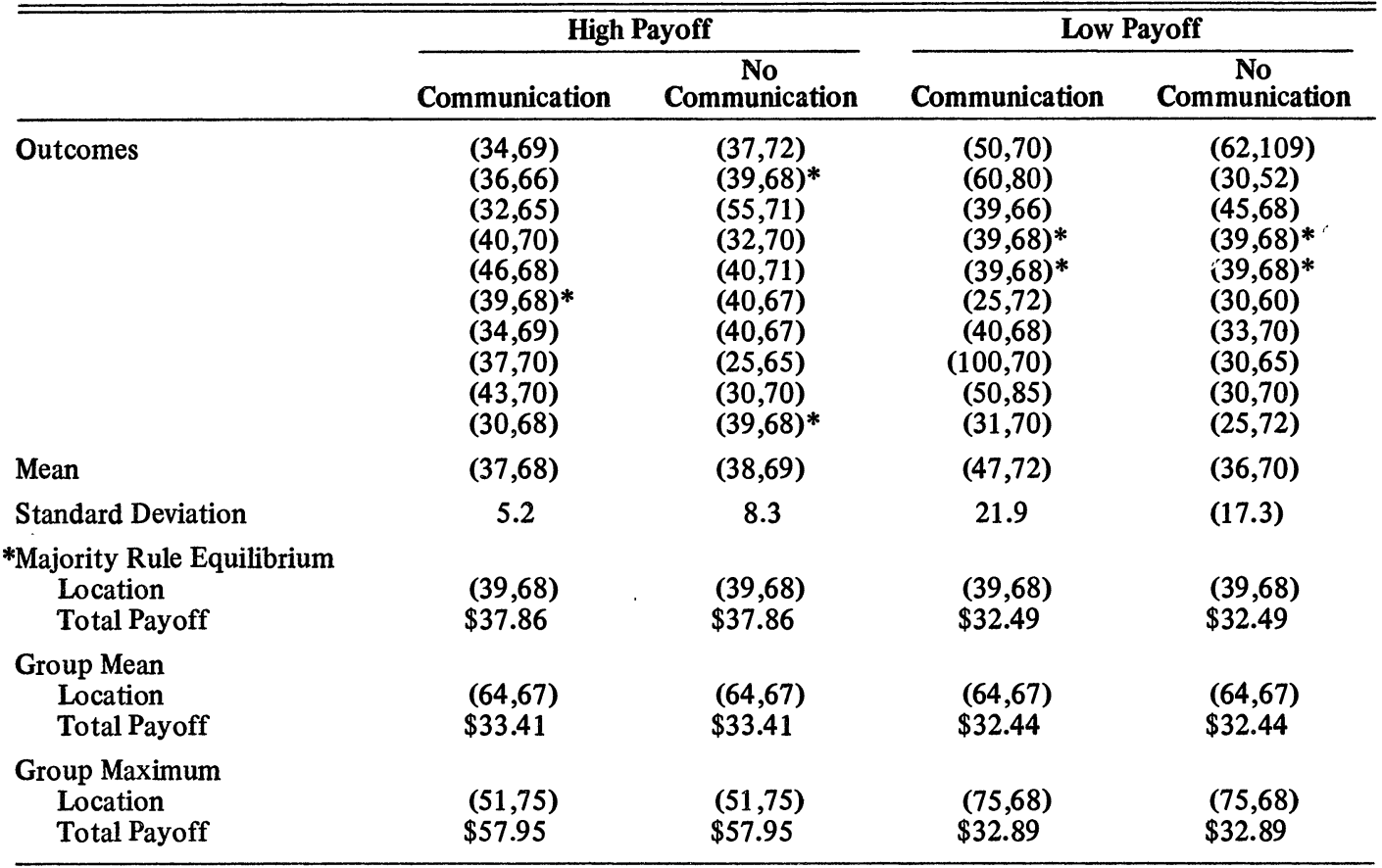

mean of the $(1,2,3)$ minimal winning coalition, two to the joint maximum of the $(1,2,3)$ coalition (although one falls outside the Pareto optimals), and the last is closest to Player 3's ideal point.

Table 1 suggests rather strongly that when individuals have a good deal at stake, one had better model their behavior via a theory which includes point $\mathrm{A}$ among its predictions. The Series 1 high-payoff experiments provide grounds for rejecting models $9-15$, in favor of $1-8,16$. Moreover, the Series 1 results also suggest a subtle way of distinguishing between models 1 and 2 , and models $3-8$. Note that the point, A, appears equally good as a prediction in both the communication and noncommunication cases. This apparently supports the view that the processes driving the results are more likely to be similar to those underlying the voting-theoretic models than to those underlying the game-theoretic models, given that the latter seem to presuppose coalitions and joint strategy choices, i.e., a generally high degree of communication and coordination.

What about the low-payoff experiments? When full communication is permitted, the mean outcome is much farther to the right (47, 72) than in the high-payoff condition. Some committees attempt to accommodate the ex- treme individual.25 Thus, charity or altruism apparently has its price and in these experiments, that price lies somewhere between a few cents and a few dollars per unit. When communication is not permitted the mean outcome is similar to that in the high-payoff case, although the variance is much higher. Thus, there is an interaction between communication and payoff conditions, with the difference between the payoff conditions being less in the absence of communication.

Overall, though, the differences in payoffs appear to be a more significant influence on the outcome of the committee process than differences in communication. Given high payoffs, the egoistic theories work equally well with or without communication. Given low payoffs, all

\footnotetext{
${ }^{25}$ Interestingly enough, this seeming altruism has an ironic twist. Subjects often made the incorrect assumption that their payoffs were identical. But the asymmetry in payoff structures (Figure 2) leads to the result that if Players 1, 2, 3 heeded the pleas of Players 4 and/or 5 to move farther north and/or east than the equilibrium, then the fringe players got significantly more in absolute terms than the more centrally located players, although the outcome remained relatively closer to the latter.
} 


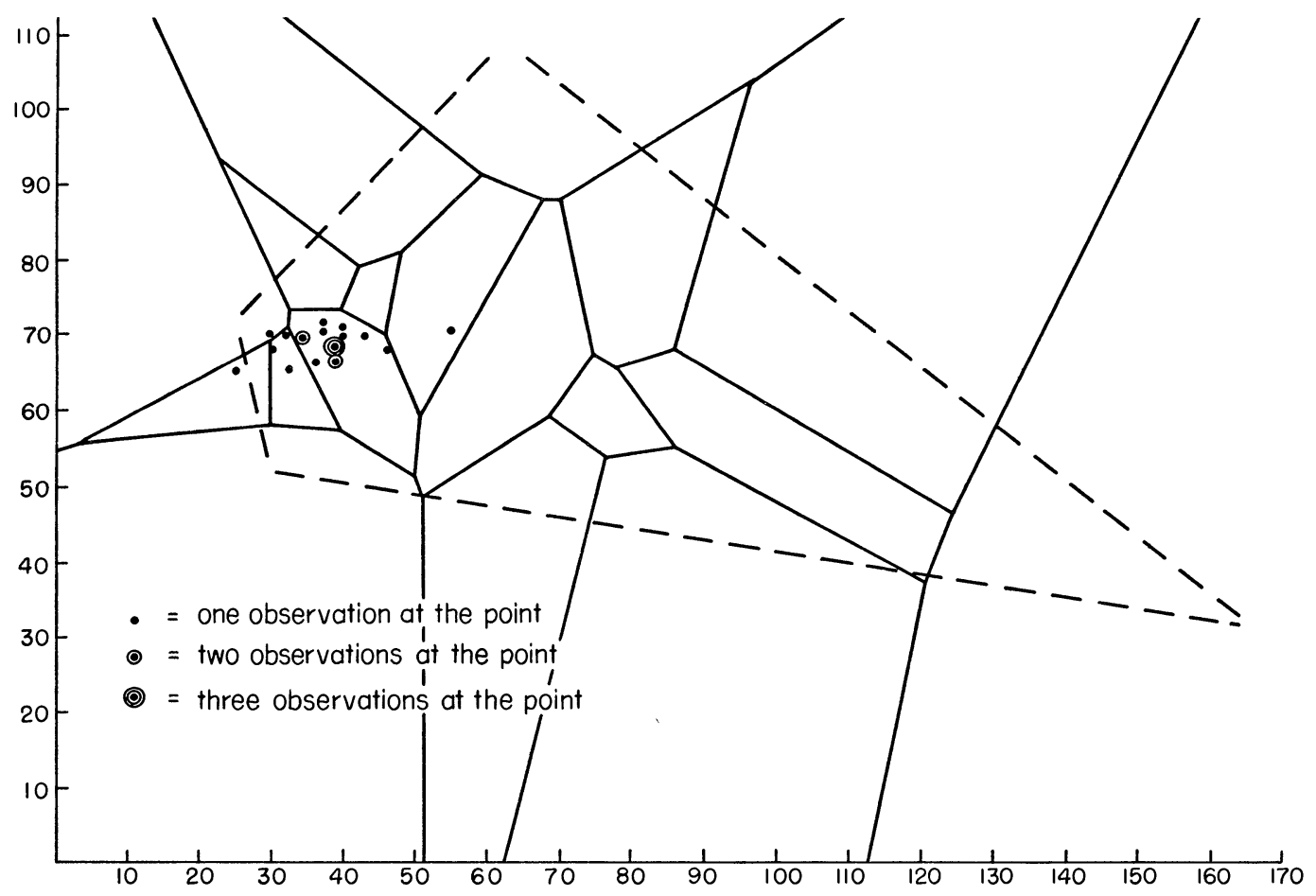

Figure 4. Series 1. High Payoff Pooled Observations

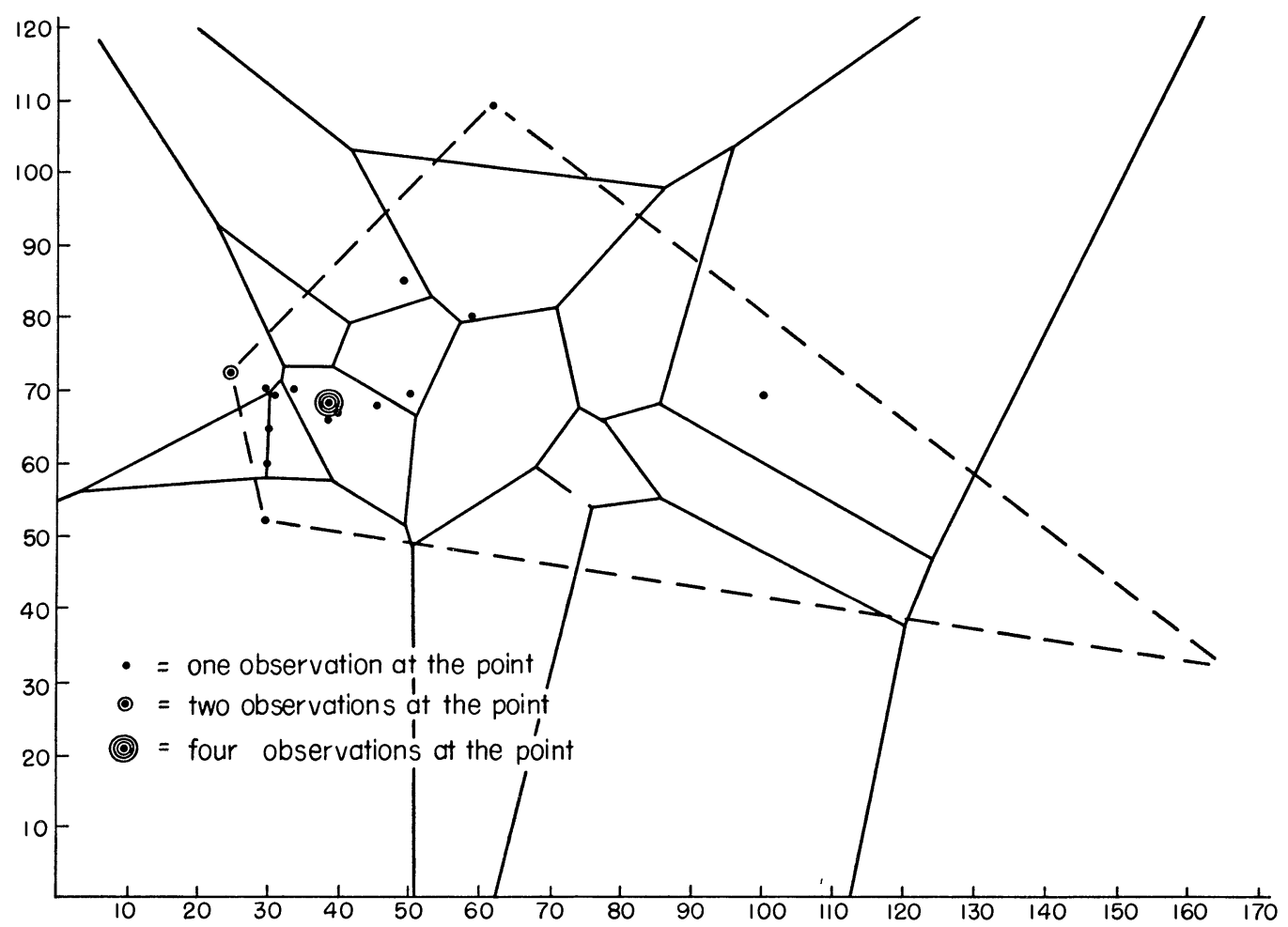

Figure 5. Series 1. Low Payoff Pooled Observations 
the models work rather poorly with or without communication. The best of a bad lot of models in the low-payoff condition are the "agenda manipulator" and the "dominant personality" models -8 of 20 outcomes fall on individual ideal points. Strangely, though, 5 of these 8 outcomes occur in the no communication case where the operation of personal factors presumably is minimal. Thus, the agenda manipulator appears to be somewhat more plausible than the personality theory.

In addition to experimental outcomes, there are other more impressionistic findings to report. As one would expect, behavior in the experiments differed between the communication and non-communication conditions. In the HP non-communication condition subjects proposed and voted on amendment after amendment (mean 28). In the communication condition the subjects made fewer official amendments (mean 16) but actually considered many more informally. Subjects often became quite involved with the decision in the communication condition. They cajoled, pleaded, sometimes wrote on the board, invented fair division schemes (usually consistent with their own self-interest) and generally created an interesting and enjoyable observational context for the experimenter. Frequently "leaders" emerged in the communication condition. These were people who took it upon themselves to gather and organize information from the other subjects and "work out" an acceptable decision. Contrary to naive expectations, these individuals did not generally do better than non-leaders.

Coalitions were very rare in the Series 1 experiments. On only a handful of occasions did we observe a subgroup of the committee arrive at a decision without regard for the wishes of the remaining committee members. The atmosphere of the experiments tended to be friendly and cooperative; irritation sometimes showed, but seldom did personal animosity surface. Even suggestions about coalitions (e.g., "let's end it; we've got the votes") typically were rebuffed by one or more committee members. Perhaps if we were to encourage subgroups of our committees to bargain privately we might find more coalitional activity, but for the experiments reported, we must conclude that coalition theories do not provide a basis for explaining either the committee processes or outcomes.

Finally, we found it interesting that subjects sometimes resorted to intellectual short-cuts such as satisficing in our experiments (e.g., "I drew this square around my ideal point and voted against anything outside of it and for anything inside"). In these experiments each subject's preferences were clearly laid out with dollars and cents figures available for each comparison of alternatives. Nevertheless, some subjects opted for simpler ways of making a decision. In the real world such difficulties are compounded. How many of us know that our preference for one Defense Procurement Bill is 3.62 and for another, 3.95? How much more likely are rule-of-thumb intellectual short-cuts in such situations? Interestingly, nearly all the formal models of committee decision processes assume away costs associated with gathering information, identifying one's preferences and reaching a decision. Yet these factors loom very large in the experiments. In the low-payoff condition the experimental atmosphere might best be described as: "Choose any reasonable point and let's go." Perhaps some concept of decision-making costs together with the equilibrium considerations that receive reasonable support in the high-payoff experiments will explain the differential Series 1 and 2 results.

Series 2. Having found three classes of models which meet with some laboratory success (egoistic game-theoretic, egoistic voting-theoretic and agenda-based voting-theoretic), we elected to continue with the high-payoff experiments and attempt to make some finer distinctions among models 1-8. Moreover, given (1) that the full-communication committees are empirically more common, and (2) that communication did not appear to make much difference with high payoffs, we also elected to continue with only full-communication experiments.

As seen in Figure 2, Series 2 differed from Series 1 in the arrangement of the individual maximums and more importantly, in the shapes (elliptical $v$. circular) of the induced indifference contours. These changes provide the opportunity for a conclusive contest between models 1-4, 6, and 5, 7, all of which made identical predictions in Series 1. In Series 2 however, model 5 (city block) predicts B with coordinates $(72,66)$. Model 7 predicts points $C$ with coordinates $(63,66)$ and $(72,61)$. Models $1-4$, and 6 predict A with coordinates $(61,69)$. Table 2 contains the experimental outcomes for Series 2, while Figure 6 illustrates them. The results are clear. The mean outcome is $(60,72)$ with a standard deviation comparable to that for Series 1. Thus, the earlier success of models 5 and 7 proves to be illusory. When their predictions coincide with models $1-4,6$, they are upheld. When models $1-4,6$, make a different prediction, models 5 and 7 fail to 
Table 2. Experimental Outcomes: Series 2

\begin{tabular}{ll}
\hline \hline Outcomes & $(70,60)$ \\
& $(60,70)$ \\
& $(61,69)^{*}$ \\
& $(54,72)$ \\
& $(61,69)^{*}$ \\
& $(60,75)$ \\
& $(65,80)$ \\
& $(61,69) *$ \\
& $(55,75)$ \\
Mean & $(55,80)$ \\
Standard Deviation & $(60,72)$ \\
*Majority Rule Equilibrium & 7.3 \\
& $(61,69)$ \\
\hline
\end{tabular}

describe the data. Although subjects sometimes use intellectual short cuts, these apparently do not involve the imposition of simpler preference structures based on the city block metric.

Two other points deserve mention. First, we now see that the Series 1 results cannot be attributed simply to the existence of a transitive, majority-rule-preference relation in that design, i.e., the fact that every sequence of proposal adoptions eventually leads to the core or equilibrium. In Series 2 cycles exist. Thus, not every sequence of proposal adoptions will necessarily lead to the core or equilibrium.

Second, notice the occurrence of non-Pareto optimal outcomes in Series 2 (2 of 10). Such "social wastage" conflicts with coalition theoretic reasoning, and indeed, with all the fundamental ideas of cooperative game theory. In contrast, such pathologies are not uncommon in voting-theoretic models. ${ }^{26}$

Series 3. Those who conduct experiments always have an informational advantage over those who only see the results, in that forces at work in the experiment may not be evident from the outcomes alone. For example, one could explain the Series 1 outcomes by appealing to game-theoretic solution concepts such as the core or Von Neumann-Morgenstern solu-

\footnotetext{
26Peter Fishburn, "Paradoxes of Voting," American Political Science Review, 68 (June 1974), $537-46$.
}

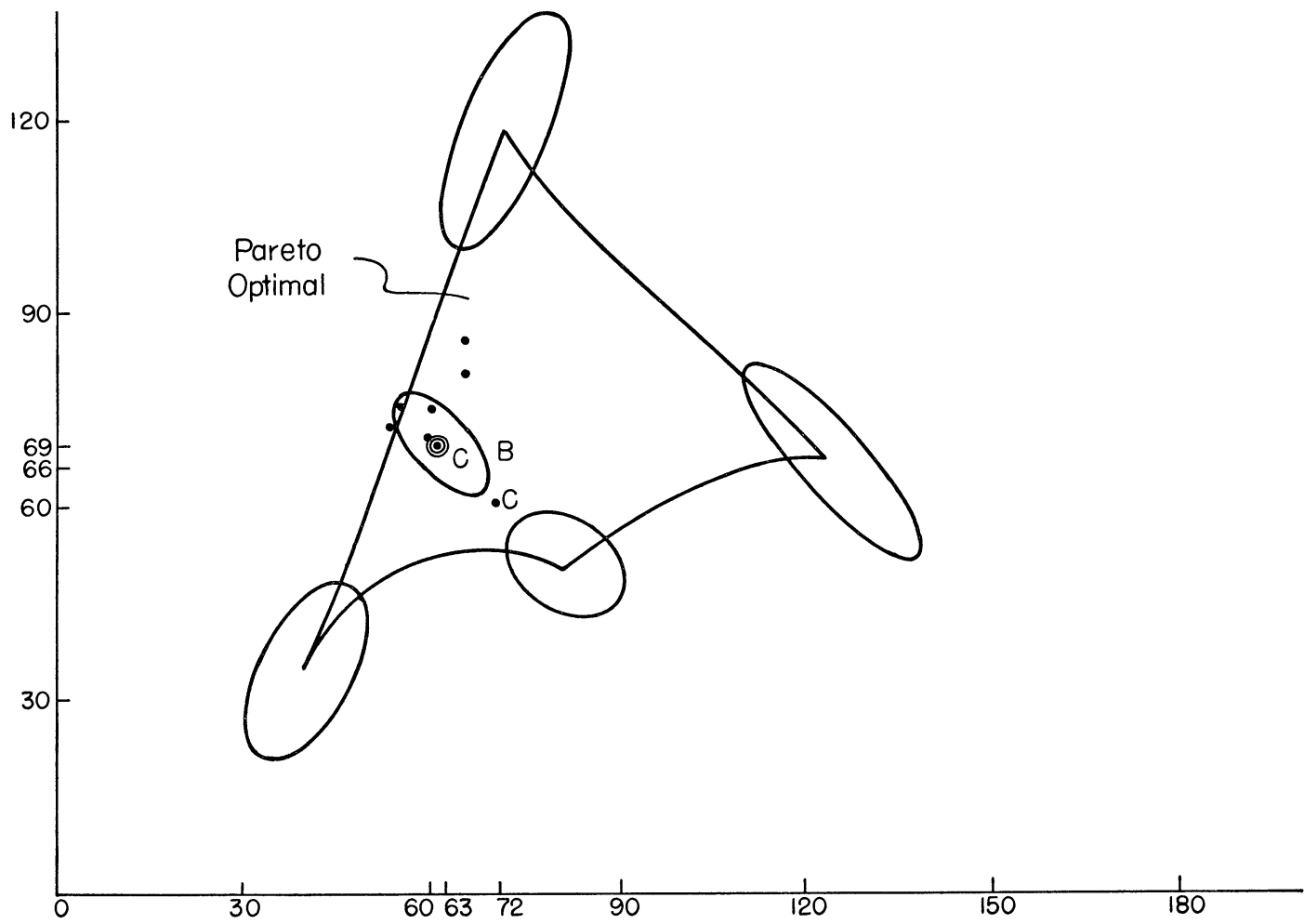

Figure 6. Series 2. Observations 
tion. As we mentioned, however, the concept of coalition, on which such solution theories depend, appears foreign to our experimental decision makers. Thus, observation of the experiments clearly aids in their explanation. In this section we report on a third series of experiments which were partially motivated by some puzzling phenomena which occurred in Series 1.

Consider Figure 7. This figure shows the "path" taken by a committee in reaching a decision. The committee in Figure 7 made six moves. Note that although the committee ended up near $(39,68)$, at some point they were exactly on it but left. According to models 1-4 the impossible happened. Thus, looking only at the experimental outcomes would lead us to a more positive appraisal of these models than would an examination of the experimental dynamics: the phenomenon illustrated in the figures is not uncommon.

How does one explain the kind of process shown in Figure 7? First, note that to move from the point $(39,68)$, at least one person must vote against his or her self-interest. Gen- erally, this is Player 1; the person whose ideal point is at the equilibrium chooses not to enforce it. Why? The experiments tend to proceed roughly as follows. Subjects begin with high hopes-many initially do not even suspect that the experimenters have placed them in conflict. A few proposals and votes quickly destroy the initial optimism. One sees frowns and hears mutterings as expectations are revised downwards. Subjects abandon hopes of getting their maximum and begin to work toward some reasonable outcome.

But what is a reasonable outcome? The alternative space contains 30,000 integer points. Only the five maxima are in any way distinguished, unless symmetry considerations point to outcomes such as $(100,75)$ which, while sometimes mentioned, are quickly dismissed. Among the maxima Player 3 at $(39,68)$ is the only one who is in any sense "centrally located." In fact, his is the only maximum in the interior of the Pareto-optimal surface. Thus, perhaps model 16 is driving the Series 1 experiments. Perhaps $(39,68)$ is a Schelling "obvious point." During the course of debate

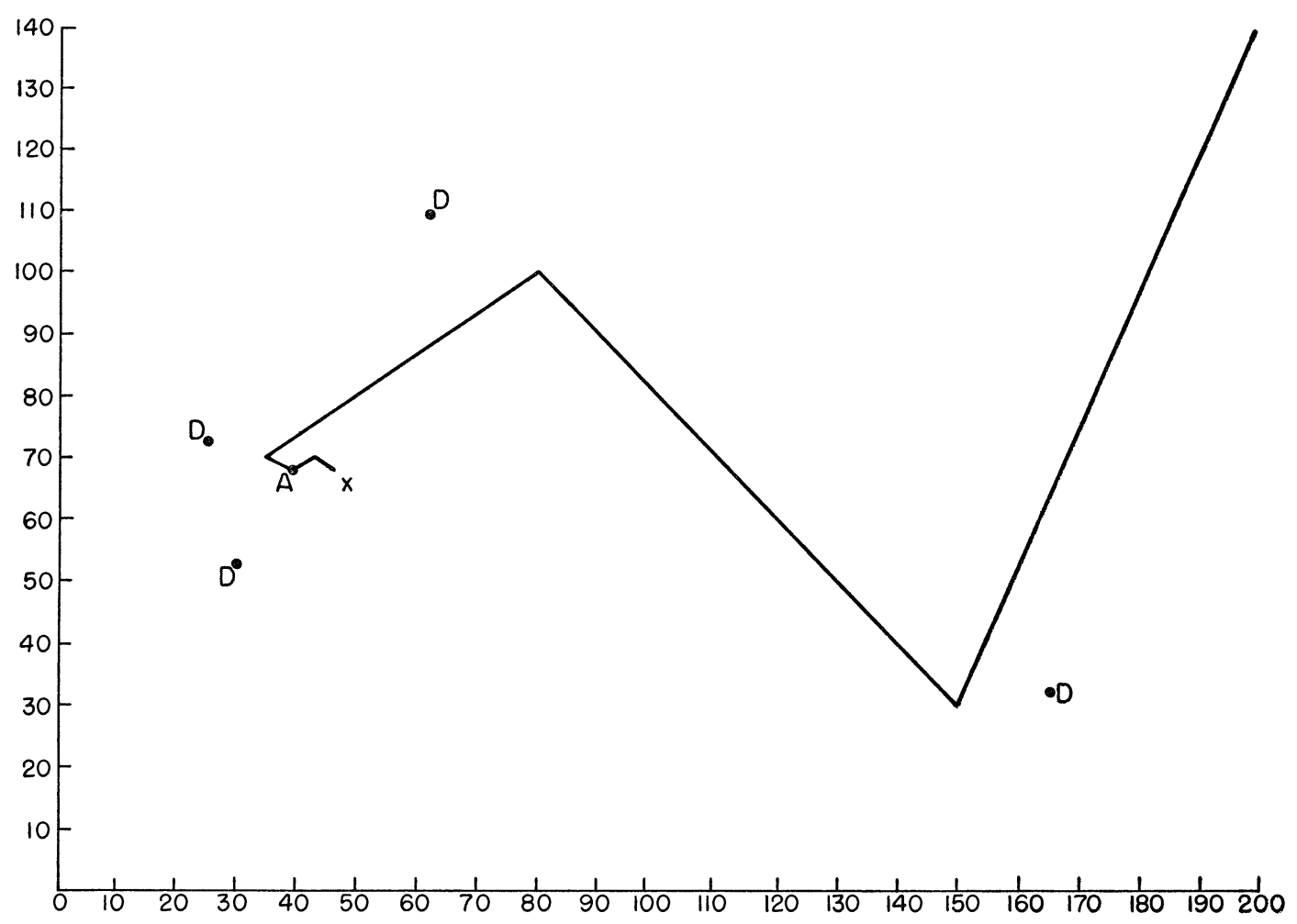

Figure 7. Sample Decision Path: From Series I-High Payoff Final Outcome: $(46,68)$ 
$(39,68)$-give or take a little to be "reasonable"-might become the "focal point" of committee members' expectations independently of its equilibrium properties. Models 1-4 might appear to predict well even though the experimental results depended on quite different consideration.

Series 3 differs from Series 1 only in that Player 1 is moved from $(39,68)$ to $(51,59)$. Although not large, this move clearly destroys the equilibrium/core. If the experimental results remain clustered and simply "follow" Player 1 to $(51,59)$, one would have grounds for rejecting the equilibrium model in favor of some coordinated expectations model. Table 3 contains the outcomes of the 15 experiments in Series 3, while Figure 8 illustrates them graphically.

Evidently, the results of Series 3 are ambiguous. To some extent the outcomes "track" Player 1 -the mean shifts outward to $(45,62)$. But Player 1's position $(51,59)$ is certainly not the mean of the experimental outcomes as in Series 1 , nor is it ever an experimental outcome. A comparison of the outcome variance yields a similarly ambiguous decision. On the one hand the standard deviation is twice as large as in the high-payoff, Series 1 experiments. But on the other hand, the outcomes
Table 3. Experimental Outcomes: Series 3

\begin{tabular}{lc}
\hline Outcomes & $(55,70)$ \\
& $(50,60)$ \\
& $(32,68)$ \\
& $(50,60)$ \\
& $(37,54)$ \\
& $(46,62)$ \\
& $(45,50)$ \\
& $(40,73)$ \\
& $(45,68)$ \\
& $(48,66)$ \\
& $(45,59)$ \\
& $(47,59)$ \\
& $(30,70)$ \\
Mean & $(51,65)$ \\
Standard Deviation & $(55,60)$ \\
& $(45,62)$ \\
& 10.3 \\
\hline
\end{tabular}

continue to cluster in a particular region, rather than fall at widely dispersed position in the space.

In a recent paper McKelvey proves a rather striking result. ${ }^{27}$ If committee members evalu-

\footnotetext{
${ }^{27}$ McKelvey, "Intransitivities in Spatial Voting Games."
}

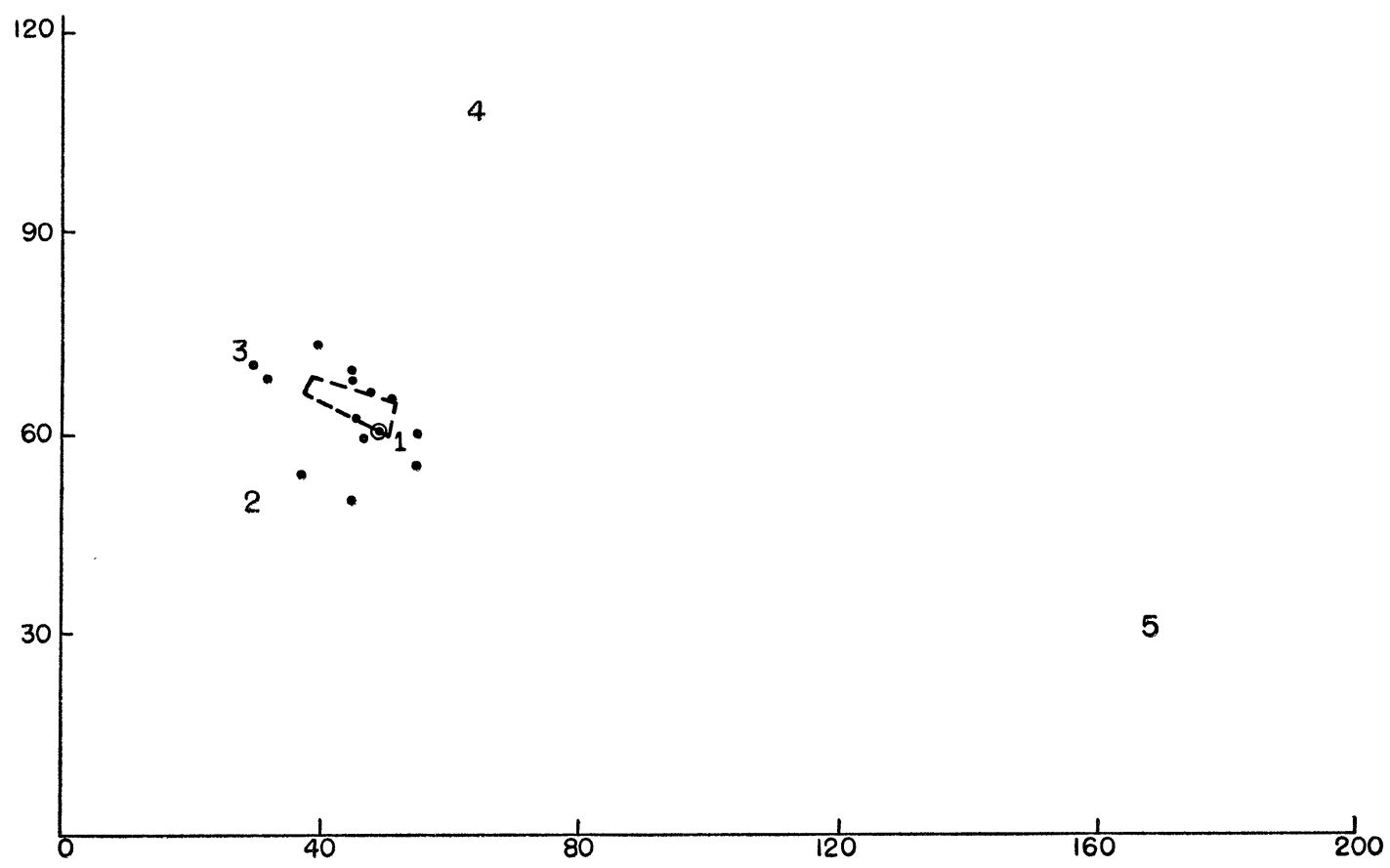

Figure 8. Series 3. Observations 
ate policies in terms of utility functions based on the Euclidean metric, then in the absence of an equilibrium, the space of potential outcomes coincides with the entire policy space. From any point in the space one can construct a sequence of alternative policies which under sincere voting lead to any arbitrarily selected point. McKelvey's result induces an interesting either-or hypothesis: if equilibrium exists, then equilibrium occurs; if not, then chaos, with the latter much more likely than the former. McKelvey conjures up the spectre purportedly exorcised by Tullock. ${ }^{28}$

Evidently, however, this pessimistic natural hypothesis induced by McKelvey's theorem is not operating in our experiments. In Series 1 the existence of an equilibrium is associated with a tightly clustered set of outcomes centered on the equilibrium. But in Series 3 the nonexistence of an equilibrium is not associated with experimental chaos. We did not notice any behavioral differences in the conduct of the two series; in particular, subjects in Series 3 appeared to have no greater difficulty in reaching a decision than did those in Series 1. Perhaps some general theory exists which could explain both Series 2 and 3 . If some as yet undeveloped theory is driving the Series 3 experiments, it had better specialize to the equilibrium/core when the latter exists. The min-max set (model 4) is one such theory, but it really does not do very well: of 15 Series 3 outcomes, only 3 are contained in it. ${ }^{29}$

In sum, Series 3 both settles and raises questions. On the one hand the pattern of results leads us to believe that model 16 is not driving the Series 1 results, that the existence of an equilibrium in Series 1 makes a real difference. On the other hand, the pattern of experimental findings does not explode, a fact which makes us wonder whether some unidentified theory is waiting to be discovered and used.

\section{Conclusions}

What have we learned from the research just described? What we expected to learn changed during the course of the project. We began with

${ }^{28}$ Gordon Tullock, "The General Irrelevance of the General Impossibility Theorem," Quarterly Journal of Economics, 81 (May 1967), 256-70.

${ }^{29}$ There are various game-theoretic solution concepts (N-M Solution, Bargaining Set, Competitive Solution) not as yet computed which also remain live candidates. the presumption that none of the models found in the literature could survive a careful experimental evaluation, that our experimental committees would produce outcomes "all over the map," so to speak. In all candor, we suspected that formal models of committee processes had little to recommend them other than logical rigor.

This negative presumption went by the board rather quickly-after a few pilot experiments, in fact. Some of the models actually appeared to work. Thus, our task changed from the easy one of generating negative results to a more difficult and painstaking one of determining why some models work, and when. This necessitated careful specification of the available models and careful design of experiments capable of differentiating among them. This conclusion summarizes the results of our first efforts, our thoughts about the significance of our results for existing theories, and the relevance of our results for applied research.

Implications for Basic Committee Research. Consider the following question: Is there a model which will predict the decision of a group under the following conditions?

a. There is no uncertainty about the consequences of any decision;

b. There is no indifference or lack of personal interest on the part of committee members;

c. The committee uses majority rule but little or no additional formal procedure such as an agenda; and

d. There are no caucuses or ex tra-committee meetings among members of the committee.

The answer: If the configuration of preferences is such that an equilibrium exists and if the preferences are strongly held, then, within narrow limits the committee's choice will be the equilibrium. If the committee members have low incentives, then several models do equally badly.

This answer implies several additional conclusions and raises some interesting additional questions:

(1) Numerous widely known models which have natural interpretations in this setting do not work. Applied scientists who wish to study situations falling within our specifications should not look to these models for help. Table 4 provides a list of the models discussed in section 4 arranged against the three experimental series. A 1 indicates a "best" model and 


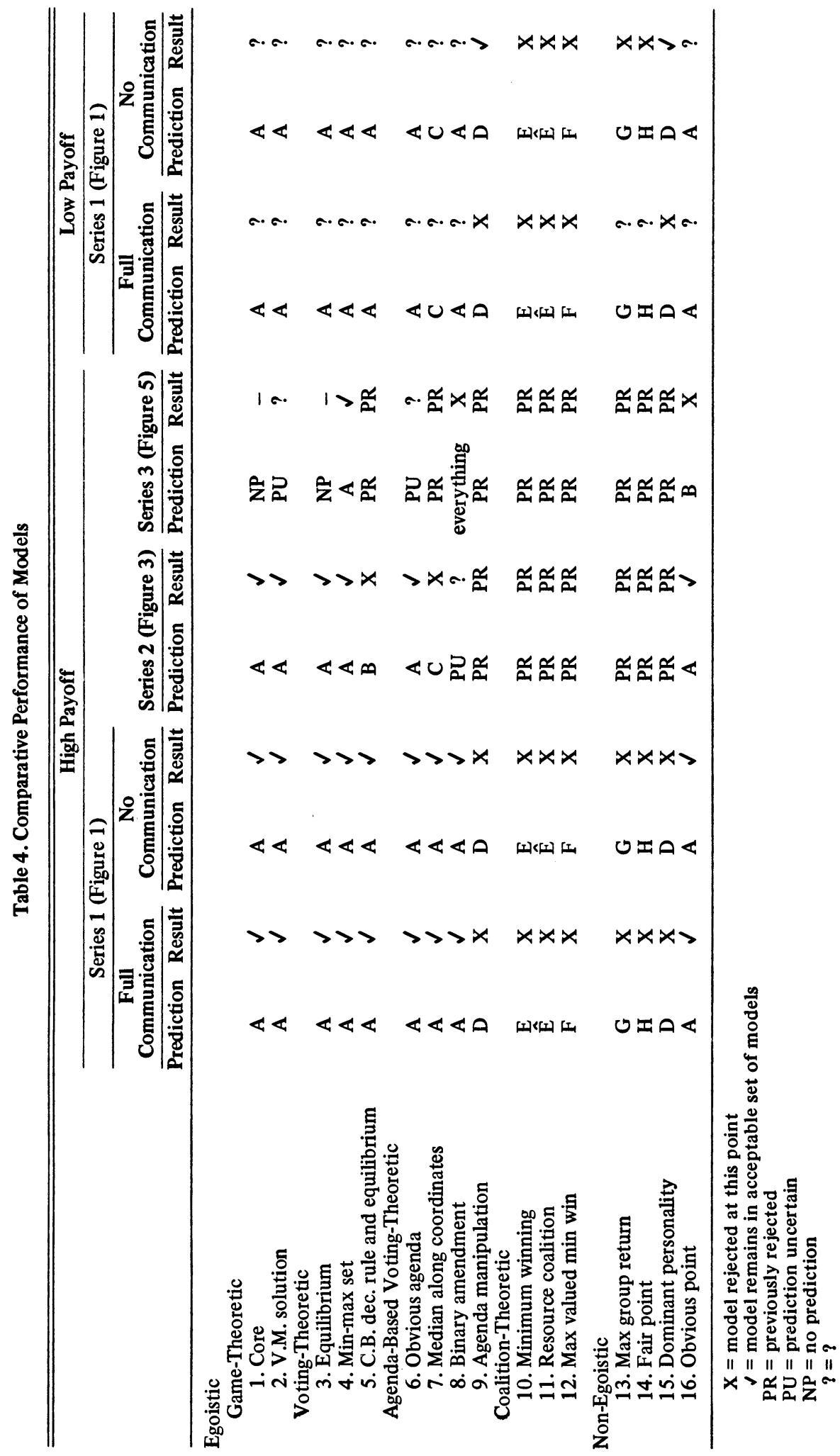


an $\mathbf{X}$ indicates a point in which a model was eliminated from further consideration.

(2) In the high-incentive case ( $\$ 1$ to $\$ 3$ per unit) coalition models, most of the agenda models and all of the non-egoistic models do a very poor job relative to equilibrium models.

(3) In the low-incentive case (1c to $5 \mathrm{c}$ per unit), if full communication is allowed, all models do poorly. Non-egoistic models, especially those based on "fairness," receive their only hint of support under these conditions. If we were forced to generalize, we would say that when people are personally indifferent or near indifferent, they try to be fair, thereby allowing the decision to be pulled further from them than the equilibrium outcome.

(4) In the low-incentive case, if no communication is allowed, all models do poorly. If we were forced to generalize we would say that the most clever agenda manipulator is the best of a poor lot. The incentives are low. People want to hurry up, vote, and go. The person who interjects a favorite motion at the proper time just might get it accepted.

(5) The fact that different models apply according to the magnitude of the incentives implies an important methodological conclusion. A large sample size will not substitute for large payoffs in differentiating between models designed for understanding high-incentive groups. ${ }^{30}$ Models intended for application in high-incentive contexts should not be rejected on the basis of data from low-payoff experiments.

(6) When an equilibrium does not exist in a high-incentive circumstance, the process does not "explode." The min-max set does best among the models considered, but only because of very weak competitors. Nevertheless, the resulting pattern of decisions seems "well contained" and suggests that a further generalization of the equilibrium notion may exist.

(7) Several ideas in the game theory literature provide models which specialize to the equilibrium when it exists and also make predictions when it does not. Application of these models requires precise operationalization of the coalition concept-a surprisingly difficult task, in our view. As mentioned, we saw little of what the literature would have us look for in

${ }^{30} \mathrm{cf}$. Anatol Rapoport and Albert Chammah, Prisoner's Dilemma (Ann Arbor: University of Michigan Press, 1965); Peter Halfpenny and Michael Taylor, "An Experimental Study of Individual and Collective Decision Making." identifying a coalition. Moreover, we observed equilibrium behavior even in the absence of communication (Series 1). Were there "phantom" coalitions at work in the latter experiments? Consider also the occurrence of nonPareto-optimal outcomes in Series 2. These are inconsistent with all theories of coalition behavior.

(8) Which of the surviving models is "really" the right one? We don't know yet. The data are consistent with four general modes of thought, that producing the core, the solution, the equilibrium and the obvious agenda. Which, if any, ultimately prove accurate remains to be determined.

(9) What will happen as conditions (a) through (d) are relaxed or varied? As uncertainty about the outcome is introduced and the group takes on a problem-solving as well as conflict-resolving aspect, members may organize themselves for purpose of information processing in a manner which induces coalition-type behavior. Such an environment, in which trust and belief loom large, may also revive the personality or other non-egoistic models. If the committee organizational environment is conducive to private meetings among subsets of members, the coalition models may receive a breath of life. But in any case we emphasize that all of these questions are resolvable within the laboratory setting.

Experiments and Applied Committee Research. A more difficult question now arises. We have indicated what we appear to have learned from the standpoint of basic science. But have we learned anything that makes a contribution to applied science? Specifically, do our experimental findings have implications for behavior in the larger political world? A significant proportion of our colleagues would undoubtedly answer in the negative. What arguments or beliefs underlie their skepticism? Having thought the matter over at some length, it seems to us that the most commonly heard arguments fall into one of three classes. ${ }^{31}$

${ }^{31}$ Actually, each of the three arguments discussed in this section is a member of a more general class which holds that the laboratory environment is artificial (the word is usually pronounced loudly and repeatedly). The specifics of the general criticism often are not spelled out-we have tried to do so in this section-but at base the criticism appears to stem from acceptance of a gestalt psychology view. That is, the subtleties of the empirical context are too many and/or too complicated to be enumerated. Moreover, these variables may interact in such a way that they 
The first argument simply asserts that "real" politicians are different from student subjects. Moreover, the argument runs, such differences are fundamental and do not merely reflect the more complex contexts in which professionals operate. This argument suggests that were we to conduct our experiments using state legislators as subjects, the experimental results would differ systematically and significantly from those previously obtained. In principle one could check the validity of the criticism by replicating the experiments using professionals as subjects. We have not done so, and therefore have no real defense against this first argument. We did use a relatively heterogeneous subject group and we encourage others to explore the bounds of the results across other populations.

The other two arguments emphasize the fact that naturally occurring political committees do not exist in splendid isolation. Instead, they are frequently embedded in some larger ongoing institutional context. This embedding raises the following potentially critical question: if the committee decision is regarded by the members as only one stage in a sequence of games, might behavior in the committee reflect strategic considerations from the larger game? If so, a model which explains the behavior in the larger game might produce implications for the committee stage which differ substantially from those implied by models successful in explaining the processes of isolated committees.

The preceding argument raises an obviously important consideration: behavior in interdependent, sequential decisions might reflect laws and principles different from those underlying behavior in isolated decisions. On balance, we think this second argument makes a convincing case for not extrapolating our results too quickly to the larger political world. We make the following observation, however. One can gradually (and carefully) complicate a research design to make it more analogous to real-world political processes. By doing so, we

are effective only when moved together-precisely the kind of variation not allowed in the controlled laboratory environment. This view must be taken seriously, and ultimately there is only one convincing rejoinder, the same that an experimentalist in the physical sciences must give to a critic who claims that the laws which operate in test tubes or other laboratory environments differ from those which operate in the "real world." One can only point to laboratorygenerated information which has been helpful in field or engineering endeavors. Granted, experimental social science has not yet progressed to such a level, but we are optimistic that it eventually will. can determine whether the complications destroy the applicability of models which work in simpler contexts. If they do, we stand a good chance of both identifying the precise complications which do the damage, and modifying the models to incorporate such complications. Thus, we do not take the second argument as a criticism of what we have done or of experimental methodology in general. Instead, it suggests that more experimental work needs to be done. We agree.

A final, third class of arguments also emphasizes the complexity and interdependence of naturally occurring political processes. Even if a model applies in principle to a naturally occurring situation, there may be no practical way to apply it. In laboratory studies we have easy access to the relevant parameters. How, in the "real world" where there are old friendships and enmities, established working relationships, debts, etc., does one identify the alternative space and the preferences over that space? For example, through exhaustive interviews and some suitable scaling technique we might construct a policy space in which a congressional committee, school board, etc., is presumably operating. Perhaps we could even approximate preferences over this space. Even so, the argument runs, isn't the policy space only a tiny subspace of the larger alternative space which includes all the aforementioned complicating factors? Clearly this is an empirical question. Answers to such questions can only come from the experience (yet to come) of trying to apply the models within the limits of prevailing measurement technology. The limits of the practical are constantly changing, presumably in a positive direction. To reject an applicable model because of the current practical difficulties of using it seems short-sighted, if not foolish.

The preceding arguments should make us cautious about assuming correspondences between laboratory and naturally occurring political behavior. But neither separately nor in combination do these arguments negate the existence of those correspondences. The irnportant thing is to resist the temptation to leap prematurely from the laboratory to the field. That transition should come through slow, well-chosen steps based on a carefully designed program which integrates theory, laboratory and field research. 


\section{Appendix A. \\ Instructions for \\ Full Communication Experiments}

General. You are about to participate in a committee process experiment in which one of numerous competing alternatives will be chosen by majority rule. The purpose of the experiment is to gain insight into certain features of complex political processes. The instructions are simple. If you follow them carefully and make good decisions, you might earn a considerable amount of money. You will be paid in cash.

Instructions to Committee Members. The alternatives are represented by points on the blackboard. The committee will adopt as the committee decision one and only one point. Your compensation depends on the particular point chosen by the committee (see attached payoff chart). For example, suppose your payoff chart is that given in Figure 1 and that the committee's final choice of alternative is the point $(x, y)=(170,50)$. Your compensation in this event would be $\$ 7,000$. If the policy of the committee is $(140,125)$ your compensation would be computed as follows:

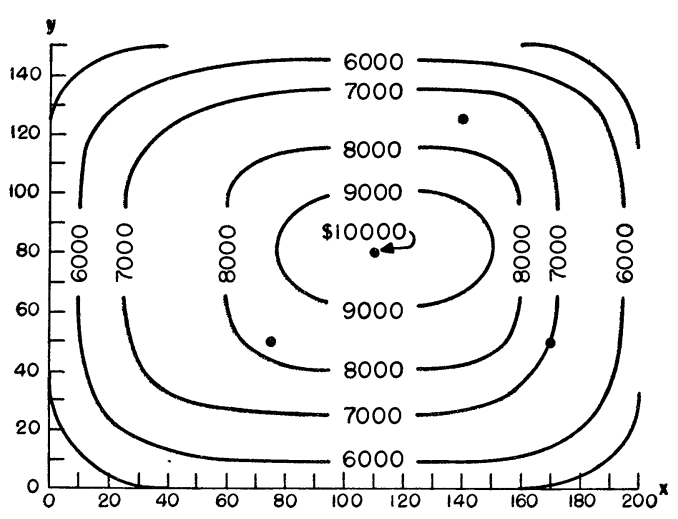

The point $(140,125)$ is halfway between the curve marked $\$ 7,000$ and the curve marked $\$ 8,000$. So, your compensation is halfway between $\$ 7,000$ and $\$ 8,000$, i.e., $\$ 7,500$. If the policy is one-quarter of the distance between two curves, then your payoff is determined by the same proportion (i.e., at $(75,50)$ which is one-quarter of the way between $\$ 8,000$ and $\$ 9,000$, you get $\$ 8,250$ ).

The compensation charts may differ among individuals. This means that the patterns of preferences differ and the monetary amounts may not be comparable. The point which would result in the highest payoff to you may not result in the highest payoff to someone else. You should decide what decision you want the committee to make and do whatever you wish within the confines of the rules to get things to go your way. The experimenters, however, are not primarily concerned with whether or how you participate so long as you stay within the confines of the rules. [Under no circumstances may you mention anything quantitative about your compensation. You are free, if you wish, to indicate which ones you like best, etc., but you cannot mention anything about the actual monetary amounts. Under no circumstances may you mention anything about activities which might involve you and other committee members after the experiment, i.e., no deals to split up afterward or no physical threats.]*

Parliamentary Rules. The process begins with an existing motion $(200,150)$ on the floor. You are free to propose amendments to this motion. Suppose, for example, $(170,50)$ is the motion on the floor and you want the group to consider the point $(140,125)$. Simply raise your hand and when you are recognized by the chair, say "I move to amend the motion to $(140,125)$." The group will then proceed to vote on the amendment. If the amendment passes by a majority vote, the point $(140,125)$ is the new motion on the floor and is subject, itself, to amendments. If the amendment fails the motion $(170,50)$ remains on the floor and is subject to further amendment. Thus, amendments simply change the motion on the floor. You may pass as many amendments as you wish.

At any time during the consideration of an amendment or the motion on the floor a motion to end debate is in order. If there are no objections, an immediate vote will take place. If there are objections, the motion to end debate will itself be put to a majority vote. If the motion to end debate fails, the amendment process continues. If it passes, a vote on the amendment or motion will take place.

To sum up, the existing motion on the floor is $(200,150)$. You are free to amend this motion as you wish. The meeting will not end until a majority consents to end debate and accept some motion. Your compensation will be determined by the motion on the floor tion. 
finally adopted by the majority.

Are there any questions?

We would like you to answer the questions

on the attached page. These should help you understand the instructions.

\section{Test}

1. At I would make the most possible money. The amount I would receive is
2. At I I would make the least possible money. The amount $I$ would receive is

3. Suppose $(200,150)$ is the motion on the floor and an amendment to move to point $(199,149)$ passes (fails), then the new motion on the floor is ___ (__ ?

4. Suppose an amendment to move to $(100,100)$ passes and no further amendments pass. If the motion on the floor is then adopted by a majority, my compensation is 


\section{Appendix B. Sample Indifference Map-Player 3, Series 1, High Payoff}

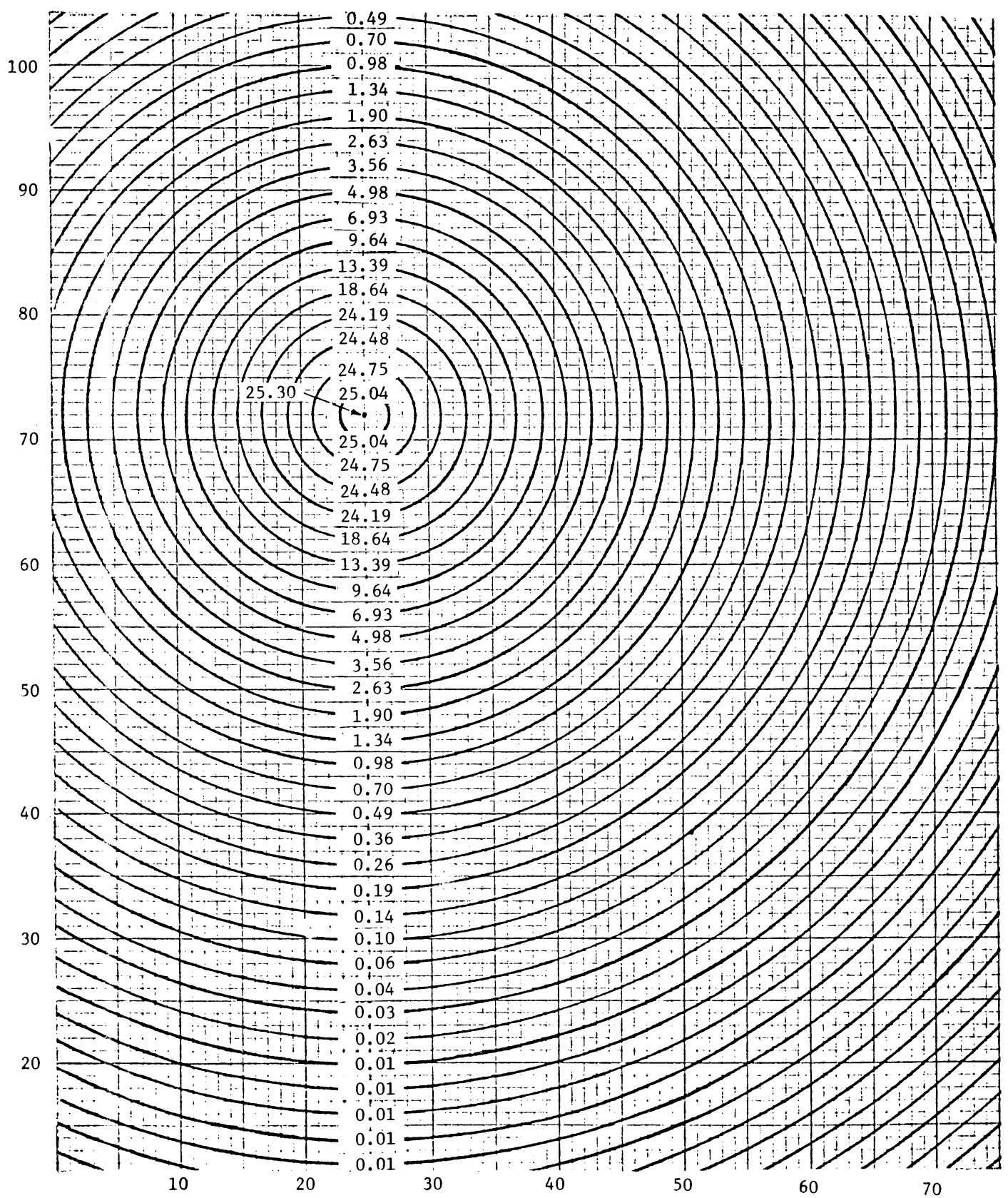




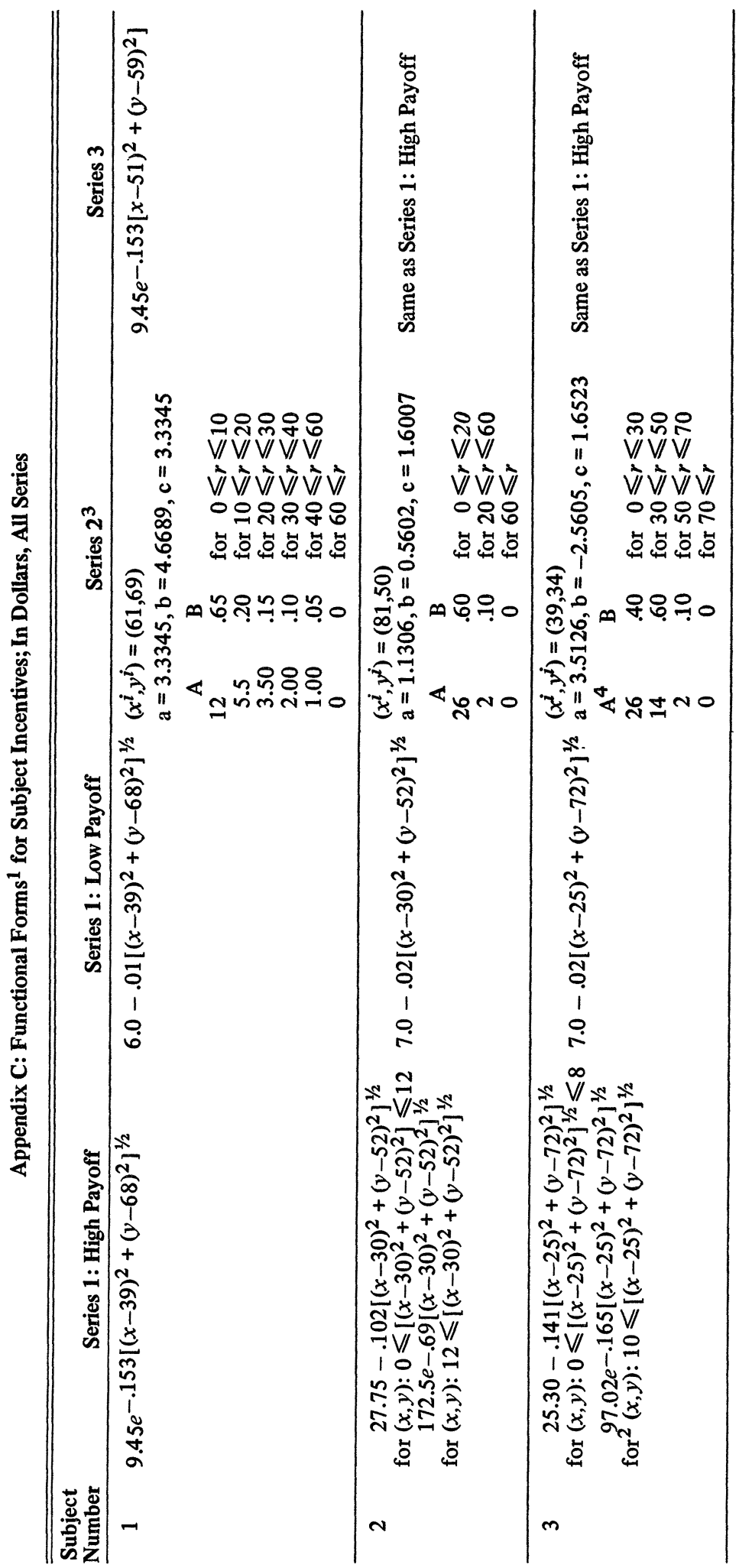




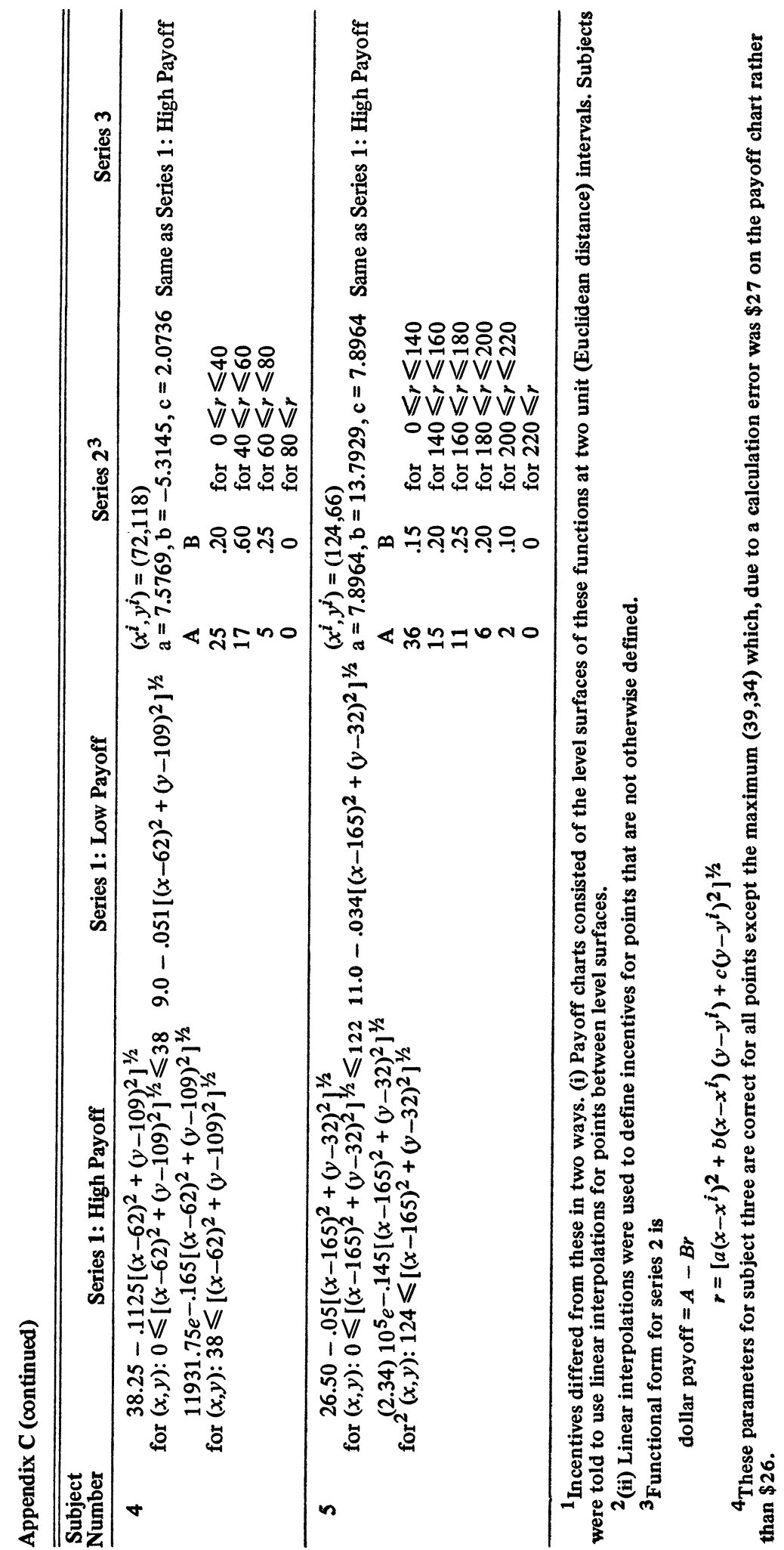

